\title{
Modeling of Microstructural Evolution in the Hot Rolling Process of Fe-16Cr-4Mn-4Ni-0.05C-0.17N Austenitic Stainless Steel
}

\author{
Murodjon Turdimatov ${ }^{1, a^{*}}$, Alexander Nam ${ }^{1, b}$, Rudolf Kawalla ${ }^{1, \mathrm{c}}$, Ulrich Prahl ${ }^{1, \mathrm{~d}}$ \\ ${ }^{1}$ Technische Universität Bergakademie Freiberg, Institute of Metal Forming, \\ Bernhard von Cotta Str 4, 09599 Freiberg, Germany \\ aMurodjon.turdimatov@imf.tu-freiberg.de, 'blexander.Nam@imf.tu-freiberg.de, \\ cRudolf.Kawalla@imf.tu-freiberg.de, dUlrich.Prahl@imf.tu-freiberg.de
}

Keywords: microstructure evolution, dynamic recrystallization, static recrystallization, grain growth

\begin{abstract}
The understanding of the softening behaviour during the hot rolling process is required to optimize the hot rolling schedule. Therefore, the microstructural evolution in the hot rolling of austenitic stainless steel was simulated. In this work, kinetics of grain growth was investigated by means of compression tests using the Gleeble HDS V40 and described by appropriate kinetic equations based on the obtained experimental results. Moreover, numerical simulation was performed using the Simufact.forming software. The results of the numerical simulation were further validated by experimental data, which were obtained from the semi-continuous hot rolling of the austenitic stainless steel.
\end{abstract}

\section{Introduction}

The evaluation of the microstructure development during and after hot deformation of metals has practical importance due to its relationship with the mechanical properties of final products. Several different processes, such as dynamic recovery (DRV), dynamic recrystallization (DRX), static recrystallization (SRX) and grain growth can influence the microstructure of deformed materials [1-7]. Semi-empirical approaches that describe softening and microstructure evolution can be integrated into numerical simulation of hot rolling processes [8]. This enables the optimization of the technological schedule and can also be used for online process control [9]. Therefore, it is important to develop accurate approaches describing the softening kinetics in order to increase the accuracy and reproducibility of the hot rolling simulation.

In this work, the grain growth kinetics of an austenitic stainless steel was investigated and a hot rolling simulation was carried out. Dynamic and static recrystallization behaviours were investigated and described by appropriate kinetic equations in previous works $[10,11]$. The aim of the simulation was to evaluate softening models that were developed in previous as well as in this work. The results of the numerical simulation were further validated by experimental data, which were obtained from hot rolling at the semi-continuous mill of the Institute of Metal forming at the TU Freiberg.

\section{Experimental Procedure}

\subsection{Material}

A nitrogen-alloyed low-nickel austenitic stainless steel was used in this research work, its detailed chemical composition is listed in Table 1 . The specimens were produced by a rod hot rolling process of the as-cast ingot with a finishing temperature higher than $1050^{\circ} \mathrm{C}$ and subsequently machined with an upset ratio diameter/height of 1.8 and a diameter of $8 \mathrm{~mm}$.

Table 1. Chemical composition of investigated steel (in weight \%)

\begin{tabular}{|c|c|c|c|c|c|c|c|}
\hline $\begin{array}{c}\text { Steel } \\
\text { name }\end{array}$ & $\mathrm{Cr}$ & $\mathrm{Mn}$ & $\mathrm{Ni}$ & $\mathrm{Si}$ & $\mathrm{C}$ & $\mathrm{N}$ & $\mathrm{Mo}$ \\
\hline $\mathrm{Mn} 4$ & 16.5 & 4.0 & 4.1 & 0.30 & 0.05 & 0.18 & 0.6 \\
\hline
\end{tabular}




\subsection{Experimental procedure}

To study grain growth kinetics, hot compression tests were performed and the specimens were quenched in water for further metallographic investigations. The hot compression tests were performed using the Gleeble HDS V40. Compression tests were carried out on cylindrical specimens. In order to minimize the friction between the specimen and the die during hot deformation, Ni-based lubricant was used. Tantalum plates were placed on the contact zones to prevent striking. The deformation temperature was captured and controlled by a Ni-CrNi thermocouple attached to the midheight surface of specimens.

In these compression tests, specimens were heated to $1190{ }^{\circ} \mathrm{C}$ at a heating rate of $3 \mathrm{~K} / \mathrm{s}$ and held for $300 \mathrm{~s}$. Then, the specimens were cooled to the deformation temperature at $5 \mathrm{~K} / \mathrm{s}$ and held for $10 \mathrm{~s}$ (Fig. 1). After deformation with a true strain of $0.15 ; 0.3 ; 0.6$ the specimens were held for delaying times $t_{p}, 1.25 t_{p}$ and $1.5 t_{p}$, where $t_{p}$ describes the delaying time for reaching a statically recrystallized fraction of $95 \%$. Delaying times at different deformation conditions were calculated using equations of static recrystallization kinetics developed in [10].

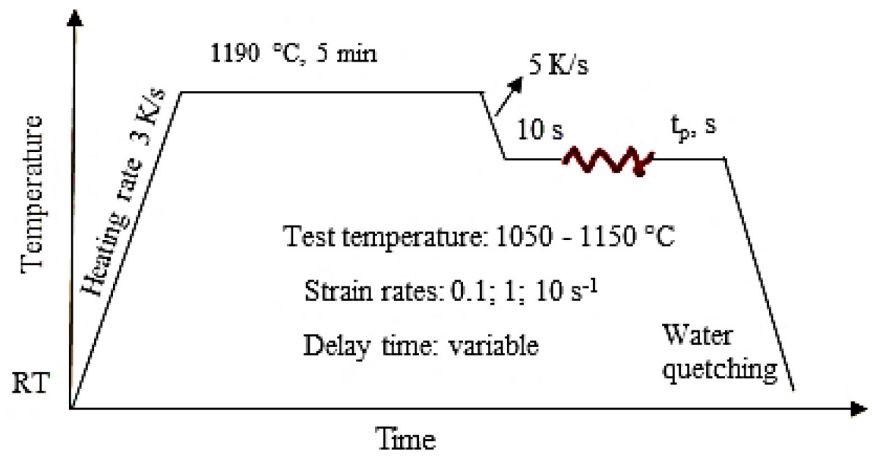

Fig. 1. Experimental procedure of compression tests to investigate the grain growth process

\section{FEM Simulation}

FEM simulation of the hot rolling test was carried out to evaluate material models (softening equations). The simulation was performed by Simufact.forming 13.3. The rolling schedule for the FEM simulation is shown in Table 2. A three dimensional FE model of the workpiece and the roll was developed for the simulation. To simplify the FE model, the simulation was performed using a $1 / 4$ part of the specimen (taking advantage of the symmetry of the sample) (Fig. 2). The sample was considered as a rigid visco-plastic material and the work roll was considered as a rigid body. Meshing of the sample was done before the first pass with 13322 hexahedral elements (1444 cross section elements and 50 elements along the longitudinal direction). Coulomb friction model was used to describe the friction condition with friction coefficients of 0.2 and 0.3 for the first three and last three rolling passes respectively. In addition, the top and bottom of the rolled material was cut after each pass, so that the strip length $L=100 \mathrm{~mm}$ remained unchanged. This further enabled the reduction of the calculation time.

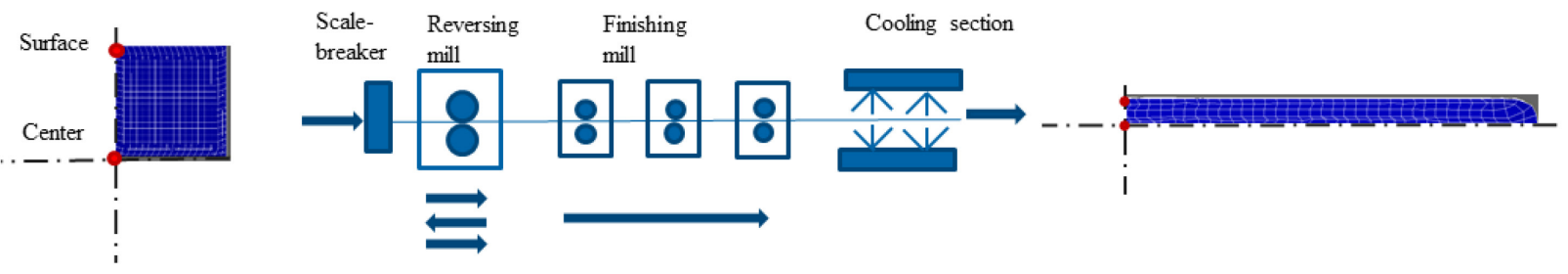

Fig. 2. Procedure of the hot rolling simulation 
Table 2. Rolling schedule for conducting the FEM simulation and laboratory rolling test

\begin{tabular}{|c|c|c|c|c|c|}
\hline Pass & $\begin{array}{c}h_{0}, \\
\mathrm{~mm}\end{array}$ & $h_{1}, \mathrm{~mm}$ & $T_{R},{ }^{\circ} \mathrm{C}$ & $\varepsilon$ & $v, \mathrm{~m} / \mathrm{s}$ \\
\hline 1 & 38 & 20 & 1102 & 0.64 & 2 \\
\hline 2 & 20.0 & 12.0 & & 0.51 & 2.0 \\
\hline 3 & 12.0 & 8.5 & & 0.34 & 2.0 \\
\hline 4 & 8.5 & 6.0 & & 0.35 & 2.0 \\
\hline 5 & 6.0 & 4.5 & & 0.29 & 3.5 \\
\hline 6 & 4.5 & 3.5 & 1060 & 0.25 & 5.0 \\
\hline \multicolumn{6}{|c|}{ Quenching in water up $<450{ }^{\circ} \mathrm{C}$} \\
\hline
\end{tabular}

The models for microstructure and grain size prediction used in the present hot rolling simulation are shown in Table 3. Equations for the descriptions of the dynamic and static recrystallization were developed in previous works $[10,11]$. To evaluate the flow stress stress-strain curves from [11] were given as tables. The coefficients of the grain growth model were determined in this work on the basis of evaluated grain sizes ( $m$ - grain growth exponent, $m=0.17 ; Q_{g}$ - activation energy for grain growth, $Q_{g}=360 \mathrm{~kJ} / \mathrm{Mol} ; G_{0}-$ material constant, $G_{0}=9.13 \cdot 10^{21} \mathrm{~m} / \mathrm{s}$ )

Tabelle 3. Microstructure prediction models used in rolling simulation

\begin{tabular}{|c|c|c|}
\hline $\begin{array}{l}\text { Dynamic } \\
\text { recrystallization model }\end{array}$ & $\begin{array}{c}Z=\dot{\varepsilon} \cdot \operatorname{Exp}\left(\frac{66429}{T}\right), \\
\varepsilon_{C}=0.0958 \cdot D_{0}^{0.00402} \cdot Z^{0.0934}, \\
X_{D R X}=1-\exp \left[-0.693 \cdot\left(\frac{\varepsilon-\varepsilon_{C}}{\varepsilon_{0.5}}\right)^{1.55}\right], \\
\varepsilon_{0,5}=0.0054 \cdot D_{0}^{0.4146} \cdot \dot{\varepsilon}^{0.0544} \exp \left(\frac{3848}{T}\right), \\
D_{D R X}=45 \cdot Z^{-0.0937}\end{array}$ & $\begin{array}{l}Z \text { Z-Zener-Hollomon } \\
\text { parameter } \\
\dot{\varepsilon} \text {-strain rate, } \mathrm{s}^{-1} \\
T \text {-temperature, } \mathrm{K} \\
\varepsilon_{\mathrm{C}} \text {-critical strain } \\
D_{0}-\text { initial grain size, } \mu \mathrm{m} \\
X_{D R X} \text { - DRX volume } \\
\text { fraction } \\
\varepsilon-\text { true strain } \\
\varepsilon_{0.5}-\text { strain required for } \\
50 \% \text { DRX } \\
D_{D R X} \text {-dynamically } \\
\text { recrystallized grain size, } \mu \mathrm{m}\end{array}$ \\
\hline $\begin{array}{ll}\text { Static } & \text { recrystallization } \\
\text { model } & \end{array}$ & $\begin{array}{c}t_{0,5}=1.087 \cdot 10^{-17} \cdot \varepsilon^{-2.66} \cdot \dot{\varepsilon}^{-0.758} \cdot D_{0}^{2.39} \cdot \exp \left(\frac{34648}{T}\right), \\
X_{S R X}=1-\exp \left[-0,693 \cdot\left(\frac{t}{t_{0,5}}\right)^{0.449}\right] \\
D_{S R X}=738.935 \cdot \varepsilon^{-0.497} \cdot D_{0}^{-0.212} \cdot Z^{-0.117}\end{array}$ & $\begin{array}{l}t 0.5-\text { time for } 50 \% \\
\text { recrystallization, } \mathrm{s} \\
X_{S R X}-\mathrm{SRX} \text { volume fraction } \\
t-\text { time, } \mathrm{s}\end{array}$ \\
\hline Grain growth model & $\mathrm{D}^{0.17}=D_{0}^{0.17}+9.13 \cdot 10^{21} \cdot t \cdot \exp \left(-\frac{43321}{T}\right)$ & $\begin{array}{l}D_{0}, D-\text { Size of the grain } \\
\text { before and after growth } \\
t \text { - time since beginning of } \\
\text { growth }\end{array}$ \\
\hline
\end{tabular}

The flow chart for the calculation of softening kinetics based on strain, strain rate, temperature and inter-pass time in the simulation is shown in Fig. 3. 


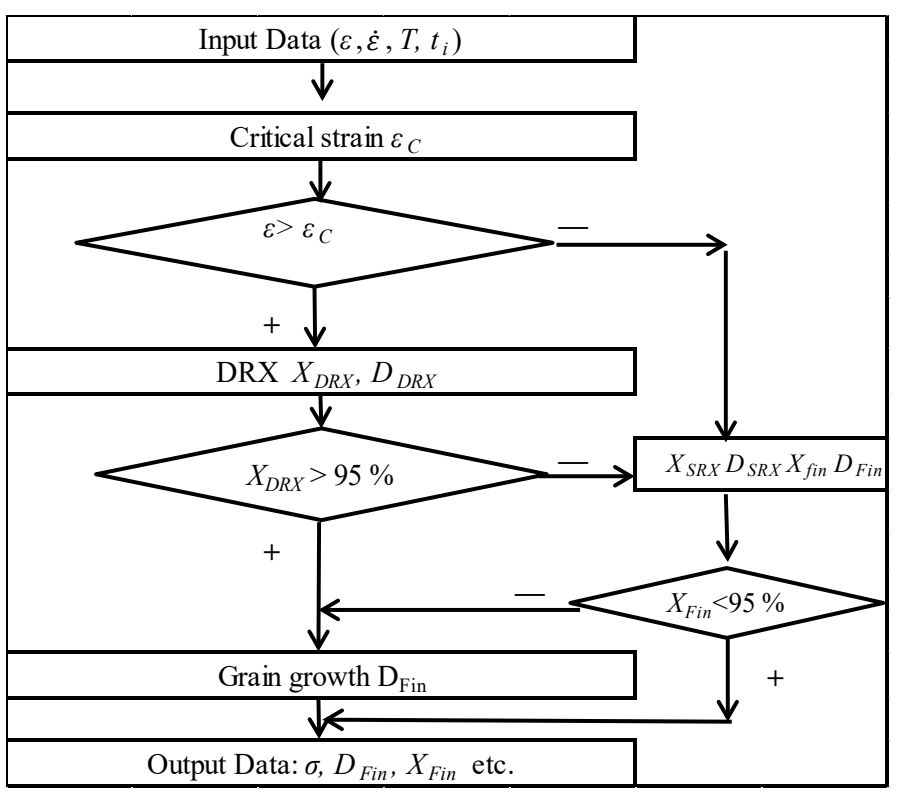

Fig. 3. Flow chart for the calculation of softening kinetics in FEM Simulation

The calculation of the dynamic and static recrystallization kinetics took place at a constant strain rate and variable temperature. Each time the temperature changes, new $\varepsilon_{0.5}$ and $t_{0.5}$ were calculated. Based on this, the strain $\varepsilon_{i-1}$ and delay time $t_{i-1}$ of the previous stage were calculated by using equations $(1-2)$.

$$
\begin{aligned}
& \varepsilon_{i-1}=\varepsilon_{C i}+\varepsilon_{0.5 i}\left(-\frac{\ln \left(1-X_{D R X(i-1)}\right)}{0.693}\right)^{\frac{1}{1.55}} . \\
& t_{i-1}=t_{0.5 i} \sqrt[0.449]{-\frac{\ln \left(1-X_{S R X(i-1)}\right)}{0.693}} .
\end{aligned}
$$

Subsequently, the current delay time and the strain were calculated using equations (3-4).

$$
\begin{aligned}
& \varepsilon_{A k}=\varepsilon_{i-1}+\left(\varepsilon_{k}-\varepsilon_{k-1}\right) . \\
& t_{A k}=t_{i-1}+\left(t_{k}-t_{k-1}\right) .
\end{aligned}
$$

If the applied strain was bigger than the critical strain $\varepsilon_{c}$ in the roll pass, but the dynamically recrystallized fraction does not reach $95 \%$, the new initial grain size $D_{0}$ for the subsequent static recrystallization was calculated from the dynamically recrystallized fraction $X_{D R X}$ according to equation (5).

$$
D_{0 i S R X}=X_{D R X i} D_{D R X i}+\left(1-X_{D R X i}\right) D_{0 i-1}
$$

The total softening fraction was calculated by following equation (6):

$$
X_{\text {Fin }}=X_{D R X}+\left(1-X_{D R X}\right) X_{S R X} \text {. }
$$

The total grain size after static recrystallization was calculated by equation (7):

$$
D_{F i n}=D_{D R X} X_{D R X}+\left(1-X_{D R X}\right) X_{S R X} D_{S R X}+\left(1-X_{D R X}\right)\left(1-X_{S R X}\right) D_{0}
$$




\section{Laboratory Rolling Tests}

The laboratory hot rolling test was carried out on the semi-continuous pilot rolling mill at the Institute of Metal Forming. (Fig. 4). For the rolling test, samples with the size of 38x38x900 mm were available in pre-rolled condition. Each sample was heated up to a temperature of $1180{ }^{\circ} \mathrm{C}$ and held at this temperature for $60 \mathrm{~min}$. Subsequently, the samples were hot rolled according to the rolling schedule and quenched in water. The rolling schedule is shown in Table 2. The surface temperature of the sample was measured using a pyrometer. The average true strain in the duo reversing mill was $\varepsilon=0.5$, whereas in the finishing mills it was $\varepsilon=0.3$.

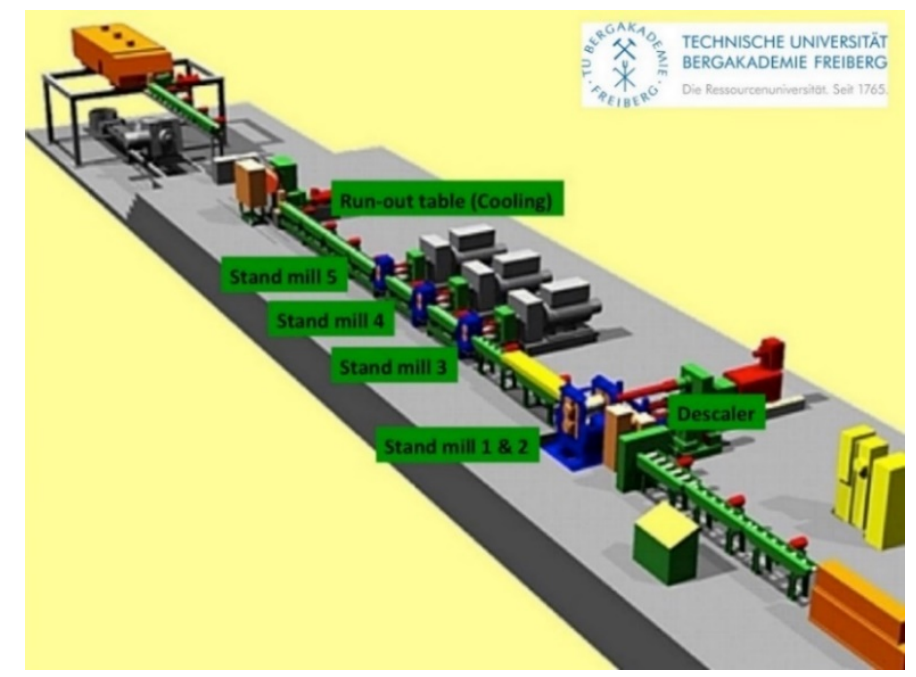

Fig. 4. Semi-continuous pilot rolling mill at the Institute of Metal Forming at the TU Freiberg

The rolling tests were carried out to validate the models of dynamic and static recrystallization and grain growth developed in this as well as in previous works $[10,11]$ under operating conditions. The starting temperature was $1100{ }^{\circ} \mathrm{C}$. The aim was to sustain a final rolling temperature of $T_{R}>950{ }^{\circ} \mathrm{C}$. Rolling temperatures below $950{ }^{\circ} \mathrm{C}$ are considered to be critical due to precipitations that may occur in this temperature range. The measured final rolling temperature of $1080{ }^{\circ} \mathrm{C}$ was in the range of the target temperature.

\section{Results and Discussion}

The calculations of microstructure development in the FEM simulation were carried out for two positions: for the surface and center of the sample cross-section (see Fig. 2). Fig. 5(a) depicts that the surface temperature of the sample decreases intensively during the forming process due to the contact with the work rolls, and then rises during the interruption time because of the temperature gradient in the cross section.

Fig. 5(b) shows the microstructural evolution during the hot rolling simulation. During deformation, the grain size decreases due to the dynamically recrystallized grains. During the interpass time, firstly the mean grain size decreases further due to the statically recrystallized grains, then after completed static recrystallization the mean grain size increases due to the grain growth process.

As shown in Fig. 5(b), the grain size on the surface is smaller than in the middle during the whole simulation process except in the first pass. This is due to the grains on the surface being formed at a lower temperature. The grain size at the end of the process reached 14.7 and $17 \mu \mathrm{m}$ for the surface and center of the sample cross section. 


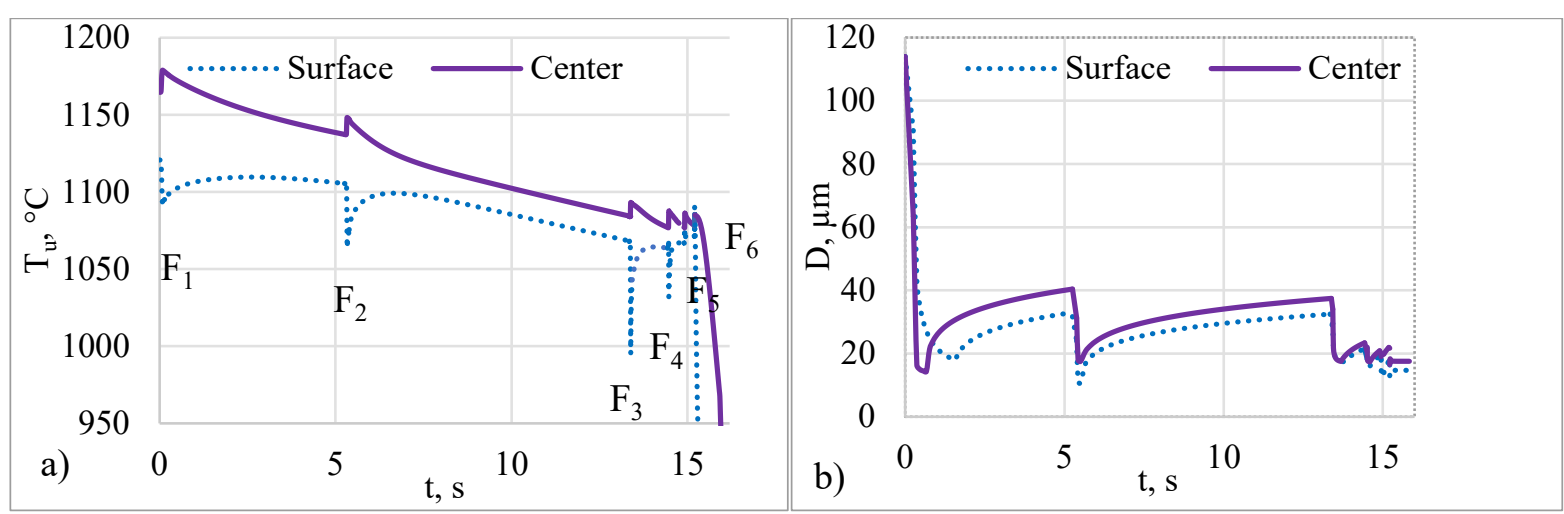

Fig. 5. Temperature (a) and grain size (b) changes during the hot rolling simulation

The Fig. 6 illustrates the deformed microstructure of the hot-rolled sample taken at the section illustrated in Fig. 7. It can be stated that the material has completely recrystallized during the given rolling schedule. The measured mean grain size was $15 \mu \mathrm{m}$.

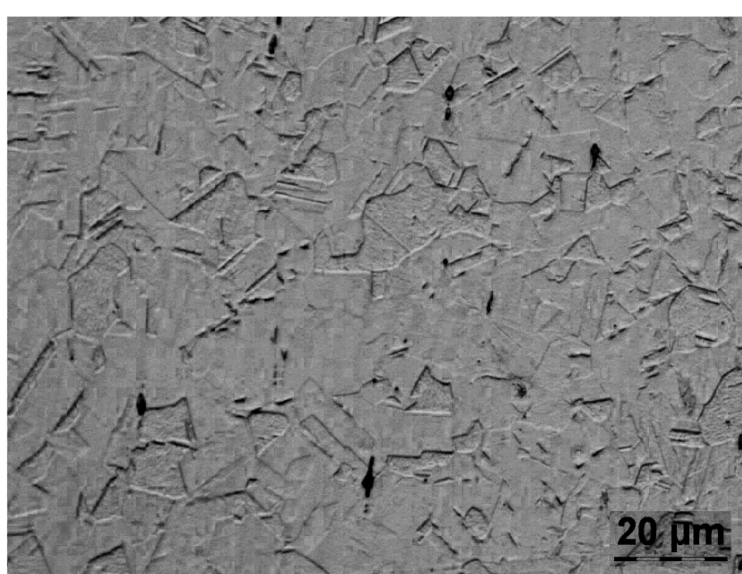

Fig. 6. Microstructure after hot rolling

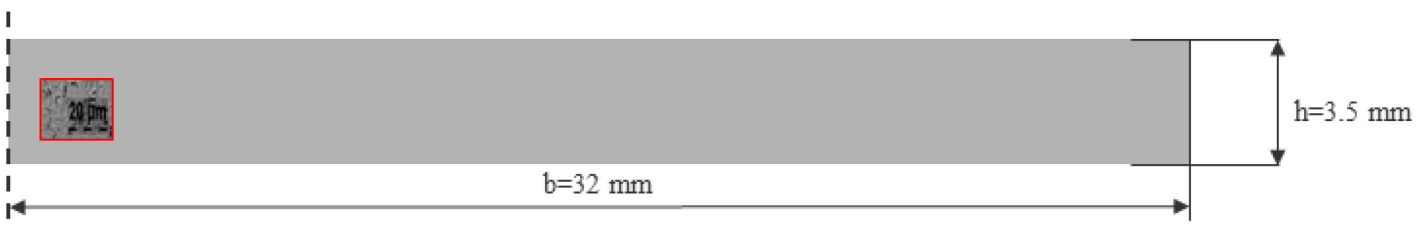

Fig. 7. Area of measured recrystallized grain size

The experimentally obtained grain size value in the hot rolling test $(D=15 \mu \mathrm{m})$ agrees with the values calculated by the FEM simulation using the softening models (14.7 and $17 \mu \mathrm{m}$ for the surface and center of the sample).

Fig. 8 shows the evolution of recrystallized fractions in the microstructure. Therefore, it can be concluded that the material was completely recrystallized after each pass. This can be attributed to the high strain and the high rolling temperature. The smallest total softening fraction of $98.5 \%$ was calculated in the sixth pass.

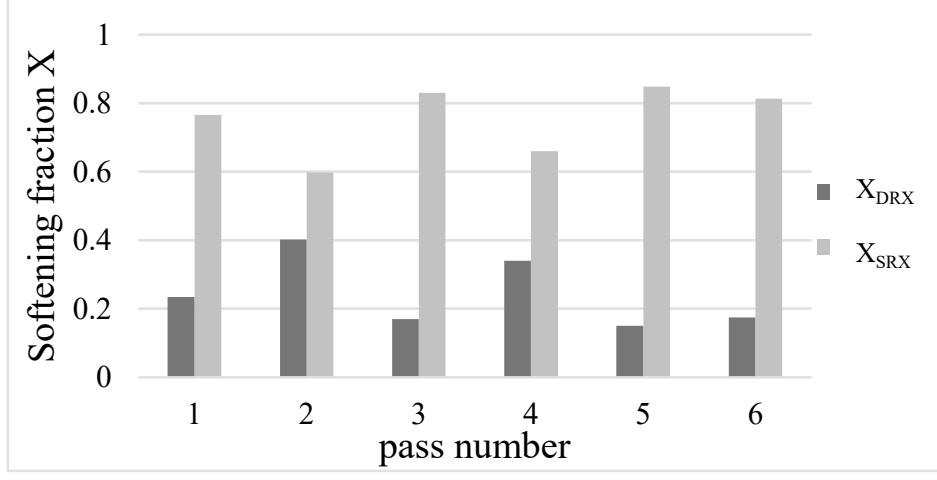

Fig. 8. Softening fraction calculated in the hot rolling simulation 
As it can be seen in Fig. 6, the structure consists of equiaxed grains. This confirms the results of the hot rolling simulation, which indicated a completely recrystallized microstructure at the end of the process.

The flow stress generated during the hot rolling simulation is shown in Fig. 9 as a function of true strain. Flow stress was calculated in Simufact.forming using given stress-strain curve, which was obtained in [11]. It can be seen that the specimen completely recrystallized and the flow stress returned to the start point after each pass. The softening proceeded basically through static recovery and recrystallization during the interruption time.

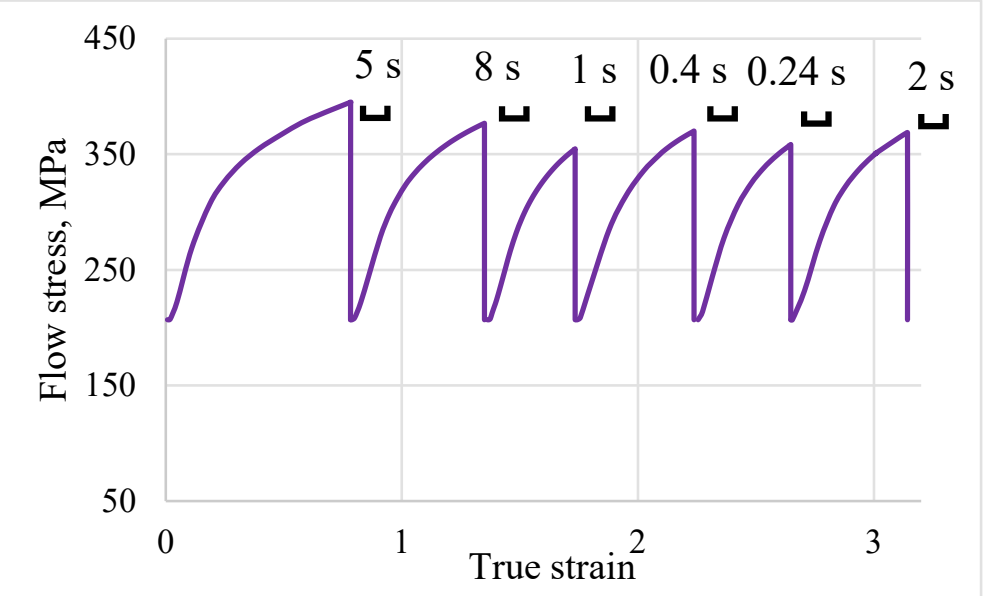

Fig. 9. Flow stress during the hot rolling simulation process

In order to validate the flow stress obtained on the basis of given flow curves, rolling forces during the hot rolling simulation and laboratory rolling test were compared for finishing rolling stages, as the flow stress is normally the most important factor affecting the rolling force during finish rolling (Fig. 10). The rolling forces in the hot rolling simulation were calculated as Z-Force, applied to the rolls of the mill. The rolling forces in the laboratory rolling test were measured with pressure indicators on both sides of the mill. Based on Fig. 10, it can be concluded one more time that the developed material models describe the rolling test appropriately.

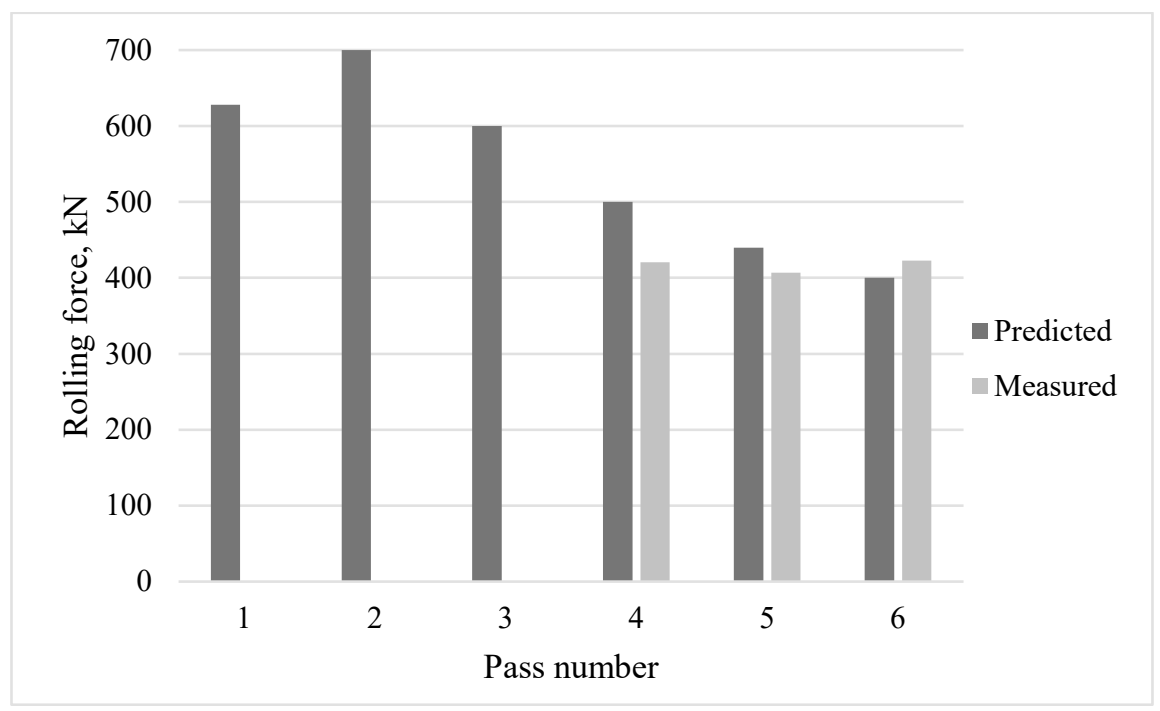

Fig. 10. Measured and predicted rolling forces

\section{Conclusions}

In this study, the microstructural evolution through the hot rolling of austenitic stainless steel was simulated. In order to be able to describe the softening behaviour after completed static recrystallization, kinetics of grain growth was investigated and described by appropriate kinetic equations. 
Subsequently, the FEM simulation and laboratory hot rolling test were carried out on the semicontinuous pilot rolling mill at the Institute of Metal Forming. The grain size value obtained in the hot rolling test $(D=15 \mu \mathrm{m})$ is in accordance with the values calculated by the FEM simulation using the softening models developed in this work (14.7 and $17 \mu \mathrm{m}$ for the surface and center of the sample). These values are within the scope of spreads. The comparison between measured rolling forces in finish rolling mills and predicted ones using Simufact shows a good degree of agreement.

A good agreement between the experimental and predicted results indicates that the proposed kinetic equations can give a precise estimate of the microstructure state of the $\mathrm{Fe}-16 \mathrm{Cr}-4 \mathrm{Mn}-4 \mathrm{Ni}-$ $0.05 \mathrm{C}-0.17 \mathrm{~N}$ steel. The results of this paper can be further applied to optimise the rolling schedule and to adjust the required final grain size and microstructure state (fully, partly recrystallized) in hot rolling processes.

\section{Acknowledgement}

The authors would like to sincerely thank the German Research Foundation (DFG-Deutsche Forschungsgemeinschaft) for funding this work as part of the Collaborative Research Centre 799 "TRIP-Matrix Composites, subproject T2".

\section{References}

[1] T. Sakai, A. Belyakov, R. Kaibyshev, H. Miura; J.J. Jonas, Dynamic and post-dynamic recrystallization under hot, cold and severe plastic deformation conditions. In: Progress in Materials Science 60 (2014), S. 130-207

[2] A. Dehghan-Manshadi, M.R. Barnett, P.D. Hodgson, Hot Deformation and Recrystallization of Austenitic Stainless Steel: Part II. Post-deformation Recrystallization. In: Metallurgical and Materials Transactions A 39 (2008), Nr. 6, S. 1371-1381

[3] M.J. Luton, C.M. Sellars, Dynamic recrystallization in nickel and nickel-iron alloys during high temperature deformation. In: Acta Metallurgica 17 (1969), Nr. 8, S. 1033-1043

[4] R. Kawalla, Einfluss der Umformbedingungen auf Rekristallisations- und Ausscheidungsverhalten nichtrostender Mo-haltiger austenitischer Stähle, VDI-Verl., Düsseldorf 1990

[5] F. Bubeck, Charakterisierung und Modellierung der Gefügeentwicklung bei der Warmumformung von Kupferwerkstoffen. Dissertation, Technische Universität Bergakademie Freiberg, Freiberg Sachsen 2007.

[6] X. Yaowen, D. Tang, S. Yong, P. Xiaogang, Prediction model for the austenite grain growth in a hot rolled dual phase steel. In: Materials \& Design 36 (2012), S. 275-278

[7] C. M. Sellars, J. A. Whiteman, Recrystallization and grain growth in hot rolling. In: Metal Science 13 (2013), 3-4, S. 187-194

[8] S. Cho, Y. Yoo, Hot rolling simulations of austenitic stainless steel. In: Journal of Materials Science 2001.

[9] Y. Meng, J. Lin, A. Yanagida, J. Yanagimoto, Modeling Static and Dynamic Kinetics of Microstructural Evolution in Hot Deformation of Fe-0.15C-0.2Si-1.4Mn-0.03Nb Alloy. In: steel research international 57 (2017), S. 1700036

[10] A. Nam, M. Turdimatov, R. Kawalla, U. Prahl, Inter-pass softening behaviour of Fe-16Cr-xMn4Ni-0.05C-0.17N. In: Advanced Engineering Materials (2018 (in revision))

[11] A. Nam, M. Turdimatov, R. Kawalla, U. Prahl, The kinetics of dynamic recrystallization of Fe16Cr-xMn-4Ni-0.05C-0.17N. In: steel research international (2018 (in revision)) 